$\mathrm{Y} \triangle \mathrm{K} 1(091)+141.131$

DOI: 10.26565/2226-0994-2018-59-1

\title{
ВАадимир Прокопенко
}

\section{БААГО И АРУГИЕ ИАЕИ ПААТОНА}

В статье анализируется учение Пцатона об идеях, рассматриваются вопросы об отношении илеи и вещи, об отношениях межАу иАеями, о местонахождении идей в разАичных диалогах П^атона. Указано на противоречивость и непоследовательность сужАений Пцатона об идеях, объясняются причины этого. Анализируется понятие блага как высшей идеи. Понятие блага изначально появляется в этике Пцатона, и только впоследствии приобретает онтологический смысл. Автор приходит к выводу о религиозной сущности идей Пкатона.

КАючевые слова: Платон, идея, благо, единое, алмегория, миф.

Платоновское учение об идеях всегда находилось в центре внимания исследователей и столетиями традиционно считалось теоретическим фундаментом учения Платона. Степень раздаботанности этой проблемы в целом чрезвычайно высока, но в последние годы все чаще встречаются попытки переосмыслить суть и значение платоновской идеологии, вплоть Ао радикального отрицания самого ее существования [напр.: Hyland, 2002]. Прояснение этого вопроса обусловливает актуальность настоящей работы. Целью нашего исследования явцяется доказательство гипотезы, согласно с которой илеи в учении Платона следует рассматривать как проекции высшей идеи блага, или истинного бытия, которая, в свою очередь, является Аля Платона не философской категорией, а высшей мифологемой и центром платоновской религии.

Выяснить, когда и в каких диалогах у Платона появляется идея блага, не представ яется возможным в силу нескольких обстоятельств. Во-первых, в лексиконе П^атона отсутствует специфический термин, означающий благо в высшем смысле, который позволил бы отАичить его от «блага»в смысле обыленном (удобство, успех, польза, выгода и т. А.). Аля всех этих случаев подходит слово agathon, которое чрезвычайно часто используется Платоном во всех его многообразных смыслах. Во-вторых, и это значительно более серьезная трудность, вряд Аи можно вообще говорить в общепринятом смысле о появлении илеи блага у Платона: тема блага присутствует в произведениях Пцатона даже тогда, когда в них обсуждаются вопросы по видимости Аалекие от этого. О чем бы ни говорилось в сочинениях Пцатона, речь всегАа идет о благе, в этой теме находят свое единство все сюжеты платоновского философствования. Справедливо было замечено, что «Аля платонизма, насколько бы универсально и широко он ни задумывался, существует лишь одна проблема, в которой сконцентрирована вся философия: проблема идеи. Но внутри этой проблемы имеется нравственное значение идеи, которое и находится в центре интереса. ИАея блага образует центр тяжести всей системы. Поэтому ее систематическая валентность Аолжна быть решающей Аля ценности и значения всего учения об идеях, с ней живет и умирает платоновский идеализм вообще» [Сеземан, 2010, с. 75]. Именно благодаря илее блага платонизм становится первым образцом философии нового типа, так рождается илеализм. Конечно, речь илет об илеализме в широком смысле слова, как о философии, открывающей Аля себя идеальное измерение бытия и которая не может быть сведена исключительно к утверждению о сотворении мира и к пресловутой «первичности идеи».

Своих учеников ПАатон знакомит с идеей блага тогАа, когда они уже подготовлены к этому знакомству дискуссиями о добродетели в сократических диалогах. Обращение к идее блага рассматривается как выход из тупика, в который привели попытки определить Аобродетель через анализ ее частных видов и случайных проявлений. В отличие от

(C) Прокопенко В. В., 2018.

(cc) $\mathbf{E Y}$ This is an open-access article distributed under the terms of the Creative Commons Attribution License 4.0. 
частных добродетелей благо Платон связывает уже не с человеком, а с богами. Бцаго имеет божественное происхожАение, оно - Аар богов Аюдям, тогАа как зАо может исходить только от человека: «бог, раз он благ, не может быть причиной всего вопреки утверждению большинства. Он причина мишь немногого Аля Аюдей, а во многом он неповинен: ведь у нас гораздо меньше хорошего, чем плохого. Причиной блага нельзя считать никого Аругого, но Аля зАа надо искать какие-то иные причины, только не бога» [Resp. 379c]. Итак, боги не посылают цюАям ничего, кроме блага, и именно благо соединяет многообразные виды добродетели в единство.

Поскольку единство добродетели достигается посредством мудрости, то и благо АОАжно быть связано с этой самой мудростью, поэтому Платон говорит об уме как условии блага, как об этом свидетельствует знаменитое рассуждение в «Федоне» [Phaed. 97c-98b]. Ум, о котором здесь илет речь, представляет собой уже не человеческую способность, но высшую мировую силу, а действие блага распространяется не только на область человеческой нравственности, но и на все мироздание: благодаря нему приходят в бытие не только человек, но и всякая вещь, вплоть до Земли, Солнца, небесных светил и всего космоса в целом.

Особенное значение в этом контексте приобретает вопрос о том, как представ яет себе Пцатон существование блага как собственно идеи, высшей идеи Единого и ТожАественного. Ведь именно благо - это то, что Аелает все существующее приемлемым и подходящим, благодаря благу возникает тот прекрасный и гармонический порядок вещей, который называют космосом, чтобы отличить его от хаоса и беспорядка, оно есть то начало, которое вообще дает возможность существованию быть существующим. Такими суждениями переполнен диалог «Филеб», который, хотя и имеет в каноне Трасилца второе название «О наслаждении», посвящен обсуждению блага не меньше, чем удовольствия. Этот Аиалог всегАа удивАял комментаторов путаностью рассуждений и многочисленными перерывами в повествовании, так что при чтении его складывается впечатление, что Пцатон несколько раз оставлял разговор, чтобы потом вновь вернуться к нему. Но именно в нем (а не в «Пире» с Трасицловым же подзаголовком «О Благе») Платон пытается дать полное определение блага и классификацию его видов. Бцаго он определяет через несколько главных признаков, характеризующих его природу - красота (kallos), соразмерность (symmetria), истина (alětheia): «Итак, если мы не в состоянии уловить благо оАной идеей, то поймаем его тремя - красотой, соразмерностью и истиной; сложив их как бы воедино, мы скажем, что это и есть действительная причина того, что содержится в смеси, и благодаря ее благости самая смесь становится благом» [Phil. 64е-65a]. Отдельное рассмотрение этих признаков, состав яющих благо, поА углом зрения их принадлежности к уму и к удовольствиям, приводит Платона к утверждению о том, что и красота, и истина, и соразмерность в большей степени причастны уму, чем удовольствию, которое бывает им и противоположно [Phil. 65b-66a]. Это чрезвычайно важное утверждение Аля понимания платоновского блага, к сожалению, во многом теряется из виду введением подробной кцассификации виАов блага, весьма путаной и неясной. Всего приводится ПАатоном пять таких видов: умеренное, прекрасное, Ум, искусства, чистые удовольствия души.

Комментаторы часто называют этот перечень иерархией, хотя так и остается неясным, в какой степени порядок перечисления соответствует важности виАов - похоже, Пцатон ограничивается только тем, что ставит удовольствие на пятое место, как можно Аальше от того, «что принадлежит к вечности». ЯвАяется Аи приведенный список полным и исчерпывающим - этот вопрос также остается без ответа, поскольку Пцатон попросту прерывает перечисление, сославшись на стих Орфея, а вскоре так же внезапно обрывается и Аиалог в целом.

ПАатон, говоря о самом важном и значительном, всегда оставляет массу недосказанного и Авусмысленного, и о благе он говорит с помощью алмегорий, которые впечатляют красотой, но не отличаются определенностью. Таково уподобление блага Солнцу, которым Платон активно пользуется в шестой книге «Государства». Смысл этой 
ацлегории очевиден: как Солнце явцяется источником света, так и благо явцяется началом Аля ума и всего умопостигаемого. Но как только мы попытаемся этим самым умом воспользоваться и слелать наше понимание блага более полным и точным, развернутым в Аеталях, то столкнемся с трудностью: непонятно, находится Аи само благо в составе умопостигаемого мира или нет? Можно понять Пцатона так: Солнце Аает жизнь всему видимому, но считать при этом видимое самим Солнцем было бы неправильно, так же и благо явАяется источником умопостигаемого, но само находится за пределами этого мира. БАаго возвышается наА миром, Аля которого оно яв яется внешней причиной. Но Пцатон Аает возможность понять его и иначе: благо может быть порожАающим началом всех илей, только если само оно является идеей и, следовательно, принадлежит к умопостигаемому миру, хотя и в особом статусе высшей иАеи, идеи всех иАей.

В космологии «Тимея» Пцатона благо появцяется уже в новом образе: благо представлено здесь как нечто очевидное и понятное без разъяснений, неслучайно в этом Аиалоге нет ни одного определения блага, а когда Пцатон говорит о благе (ЕАином, Тождественном и проч.), он обращается с ним как с вещью, а не идеей, примером чего может служить решение вопроса о единстве Тождественного и Иного в идее БАага: после безуспешной попытки соединить эти Аве идеи посредством диалектических рассуждений, преАпринятой в «Пармениде», Платон меняет способ отношения к проблеме, и в «Тимее» она разрешается очень мегко - Аемиург попросту смешивает эти две природы, затем разделяет их, устанавАивая пропорции и обращаясь с идеями подобно тому, как гончар обращается с глиной.

С осмыслением идеи блага у Пцатона непосредственно связаны и все его многочисленные рассужАения, которые впоследствии были неточно названы теорией идей. Как давно было замечено, собственно теории идей у Пцатона не найти, но и считать все то, что он говорит об идеях (еidoi) чем-то несущественным, нельзя, а илея представляет собой чрезвычайно значимое Аля Пцатона понятие. Что такое идея Аля Пцатона, можно прояснить хотя бы отчасти, установив основные значения, в которых этот термин у него используется. Известно, что у Пцатона встречаются два основных слова Аля выражения понятия «идея» (eidos и idea), которые далеко не всегда явцяются синонимами, что подтвержАается многочисленными исследованиями. Хорошо известен опыт такого исследования, предпринятый А. Ф. Аосевым, который настаивает на серьезных смысловых различиях межАу этими Авумя понятиями: «Если фиксируется оформленность смыгллового лика с точки зрения ее отличия от всякого иного лика, то такая оформленность есть эйдетическая, эйдос; если же оформленность выгдвигется с точки зрения ее полученности и смыслового происхождения из отдельныхх частей или моментов, то такая оформленность есть идеальная, идея. Эйлос есть смысловая организация на фоне Аругих смысловых организаций, почему всякий эйлос несет на себе момент выделенности из всего прочего, отличенности от всего прочего, дифференщиальности. ИАея есть смысловая организация, получающаяся от смыслового соединения Аругих, более мелких, эйдетических оформлений, частей, элементов, почему всякая идея несет на себе момент объединенности, сложенности, нарочитой организованности, интегральности. Это и значит, что эйлос имеет дифференциальную, идея же - интегральную природу» [Аосев, 1993, с. 272].

Такие тонкие Аистинкции в нашем случае будут, наверное, изАишними, поскольку оба эти слова, которыми пользуется Пцатон, этимологически родственны и восходят к одному источнику, глаголу idein (видеть), а сам Платон, похоже, в большинстве случаев игнорировал смысловые оттенки, различающие eidos и idea. В англоязычной митературе о Пıатоне широкое распространение получиц своеобразный терминологический компромисс, когАа разАичие эйдоса и идеи не акцентируется, а Аля обоих слов используется один и тот же английский эквивалент «form» (форма), который, конечно, уступает греческому оригиналу в богатстве содержания, но зато подчеркивает очень важный смысловой аспект видимости, который полностью теряется, к примеру, в русском «иАея». Ведь, Аействительно, Пцатон говорит об eidos-idea как о том, что об̆ладает 
очертаниями, границами, разАичимостью на фоне, то есть всем тем, что характеризует форму, причем не в переносном, а в прямом смысле. ИАея есть нечто видимое, доступное

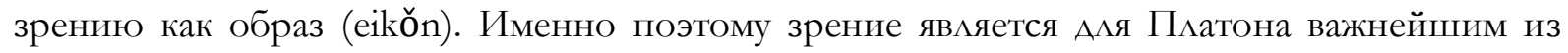
чувств, которому он отдает предпочтение, когда речь идет о высших родах знания. Конечно, говорится не об обычном зрении, которому в опыте чувственного восприятия Аоступны мишь мелькающие изменчивые, пестрые образы вещей, - Аля такого чувственного зрения илеи как раз оказываются «безвидными и незримыми», а об особом зрении-созерцании, когда смотрят глазами Ауши (psyche theateon): «у нас есть неоспоримые доказательства, что Аостигнуть чистого знания чего бы то ни было мы не можем иначе как отрешившись от тела и созерцая вещи сами по себе самою по себе Аушой» [Phaed. 66e].

«Зрение Ауши» направлено на объекты, которые Платон в приведенном выше фрагменте называет «вещи сами по себе» (auta ta pragmata), и это определение чрезвычайно важно Аля понимания того, что собой преАставАяют идеи ПАатона. ИАея как вещь сама по себе, в отличие от чувственной вещи, существует независимо от внешних условий и отношений, она - то самое неизменное и вечное, о котором в «Тимее» П^атон говорит, что оно есть бытие, «не имеющее возникновения». ИАеи - вечные сущности, не возникшие и неуничтожимые (ведь, то, что не возникло, не подвержено и уничтожению), они не принадлежат к миру «возникшего» (physis), о котором Платон там же, в «Тимее», говорит, что он есть «вечно возникающее, но никогАа не сущее». Пцатон говорит об идеях как о вечных, неизменных и неподвижных сущностях, которые недоступны чувствам, но видимы одним только умом. Аругие свойства идей, о которых идет речь у Платона, раскрываются при сравнении их с вещами, то есть чувственно воспринимаемыми предметами. Во-первых, в противоположность множественным вещам, идея понимается как некое общее (единое). Во-вторых, идея относится к вещи как образец (paradeigma) к копии. Этот образец совершенен, в то время, как ни одна из вещей не может быть такой, поскольку вещи индивидуальны, а не универсальны. Кроме того, вещи подвержены постоянному изменению, а Аля Платона всякое изменение ведет к отклонению от первоначального идеального образа вещи, а значит - к ухудшению ее. Закономерным финалом всякого изменения Аля того, что способно изменяться, становится его смерть и исчезновение. В-третьих, сущность вещи, ее смысл и цель определяется причастностью (methexis) ее к определенной идее.

Вот это, собственно, и все, что с минимальной определенностью говорится П^атоном об илеях, причем в большинстве диалогов никакие илеи специально не рассматриваются, речь о них идет только в четырех диалогах («Государство», «Пир», «Федон» и «ФеАр»), к которым следует Аобавить, конечно, «ПармениА». Правда, результат исследования отношений илеи и вещи в «Пармениде» никак нельзя назвать определенным и положительным, он скорее представ яет собой колАекцию непреодолимых трудностей и противоречий, которые Платон собрал и оставиц без какого-либо ответа. Оказалось, что вещь не может быть причастной идее ни одним из возможных способов, но отказаться на этом основании от признания идей тоже невозможно: «... если кто, приняв во внимание все только что изложенное и т. п., откажется допустить, что существуют идеи вещей, и не станет определять идеи каждой вещи в отдельности, то, не Аопуская постоянно тожАественной себе идеи каждой из существующих вещей, он не найдет, куда направить свою мысль, и тем самым уничтожит всякую возможность рассужАения» [Parm. 135c]. Остались без ответа и Аругие вопросы, например, о возможности существования вещей без их причастности к идее в случае, когда очевидное безобразие и ничтожность вещи противоречит требованию мыслить илею как совершенную.

Точно так же оказывается, что идею нельзя понимать как мысль (а такое понимание сильно упростило бы жизнь сторонникам учения об илеях), при этом опровержение этой гипотезы [Parm. 132b-d] построено Пцатоном так, что Аискуссии относительно его аргументации не прекращаются до сих пор. Понимание идей как образцов, которым 
уподоблены вещи, теперь им опровергается [Parm. 132d-133], причем, весьма убедительный аргумент о том, что такое понимание идей неизбежно приведет к бесконечному их умножению, позднее был повторен Аристотелем. А самым разрушительным по своим последствиям стало перенесение Пцатоном области поиска с отношения «идея - вещь» на отношение межАу идеями - ЕАиного как идеи идей и Иного как идеи множественного, изменчивого, временного, всего, что присуще вещам. Тщательный анализ понятия ЕАиного по нескольким предположениям (Прокл насчитал восемь таких основных гипотез) показал, что Единое может быть единым, а не множественным, только не участвуя в бытии, т.е. не существуя, а, наоборот, признание участия ЕАиного в бытии ведет к тому, что оно перестает быть единым и становится множественным. МежАу тем, констатирует Пцатон, Иного нет без ЕАиного и, вообще, «если еАиное не существует, то ничего не существует» [Parm. 166c].

Итак, существование идей А^я ПАатона критически важно, он постоянно говорит об илеях, несмотря на то, что не может обосновать их существование, объяснить их отношения с вещами и отношения межАу самими идеями. В диалогах встречаются самые разнообразные, иногда - взаимоисключающие суждения по этим вопросам, поэтому интерпретаторы всегда испытывали трудности с определением некой «истинной позиции» Пцатона. Ясно, однако, что тот образ платоновского учения об идеях, который восходит к историко-философской науке второй половины XIX - начала XX века и еще и сегодня часто воспринимается как единственно правильная и естественная, «стандартная» версия, не выдерживает критики. Эта версия основана на нескольких довольно грубых упрощениях. Первое: Пцатон якобы предпринимает своеобразное «удвоение мира», когда наряду с миром вещей, а точнее, наА этим миром, выстраивает мир идей, трансцендентный по отношению к чувственной реальности. Чувственный мир отличается от мира идей меньшей степенью реальности и, возможно, он вообще является всего Аишь виАимостью. Второе: иАеи явцяются источником бытия вещей, которые возникают как подобия или копии идей. ИАеи явАяются источником этого возникновения вещей иАи, по крайней мере, их «порожАающими моделями» (термин А. Ф. Аосева). Третье: сами идеи образуют иерархическую структуру, в которой частные, меньшего уровня общности, иАеи порожАаются Аругими, более общими идеями, а те, в свою очередь - высшей идеей, «эйАосом эйАОсов», ЕАиным, БАагом.

Ошибочность такого представления о платоновской философии не означает, что оно неверно фактически - практически все приведенные выше утверждения можно обосновать ссылками на различные места в диалогах Пцатона, но это представление односторонне и неполно. Принципиальная открытость платоновской манеры изложения выражает открытость и многозначность философского мышления Пцатона, который оставляет так много вариантов развития учения об идеях, намеченных с разной степенью отчетливости, что свести все это богатство к однозначной схеме не представАяется возможным. Например, каков будет платоновский ответ на вопрос о месте существования илей? Ясно, что пространство и время, в котором пребывают вещи чувственного мира, чужды вечной природе идей, и ПАатон отводит идеям место в некой «умопостигаемой области». Аегко представить, что это «умное место» в собственном смысле слова нигде не находится, Аа и сам Пцатон говорит в «Тимее» о том, что, когда мы думаем, что бытие обязательно Аолжно находиться в каком-то месте и занимать какое-то пространство, а то, что не находится ни на земле, ни на небесах, будто бы и не существует, мы как бы в грезах переносим на истинное бытие непричастную ему природу. Но с Аругой стороны, соб̆ственное место Амя умопостигаемого бытия все же нашлось, и в «ФеАре» Платон говорит о некой «занебесной области» (topos hyperouranios): «Эту область занимает бесцветная, Аишенная очертаний, неосязаемая сущность, подлинно сущая, зримая Аишь кормчему Ауши - разуму: на нее-то и направлено истинное знание» [Phaedr. 247d]. Положение о трансцендентности идей может быть многократно подтвержАено словами П^атона, он часто говорит о существовании идей отдельно от чувственного мира. Но ведь 
именно положение об отАельном Аруг от Аруга существовании мира вещей и мира иАей стало в первой части «ПармениАа» предметом жесткой критики, и Платон, доказав, в конце концов, неприемлемость этого тезиса, оставиц его элеатам. Кроме того, если идеи и вещи существуют отдельно в непересекающихся мирах, то о какой причастности вещей к идеям вообще может иАти речь? Ведь трансцендентные чувственному миру идеи не только оказываются бесполезны Аля бытия вещей, но и ничего не Аают Аля их познания - эти аргументы впоследствии выдвинет против платоновского учения об идеях Аристотель (который, надо сказать, и был одним из главных конструкторов этого самого учения). Значит ли это, что мир идей вовсе не отделен от чувственного мира вещей, а идеи какимто образом занимают свое место в том же мире, что и вещи? И А৯я такого понимания тоже можно отыскать основания в текстах Пцатона, которые позволили, например, А. Ф. Аосеву утверждать, что у Платона идеальное и телесное, чувственное, слиты в еАином существовании.

Непоследовательные и противоречивые рассуждения Платона о существовании идей предоставАяют интерпретаторам почти неограниченные возможности выдвижения различных вариантов представления платоновских идей и отношения их к вещам чувственного мира, и кажется, что в этих вопросах Платон испытывает полное равнодушие к тому, чтобы быть понятым однозначно. «Теория идей Платона», склеенный из различных фрагментов платоновских текстов философский гомункулус, Аопускает многообразные истолкования: первая в мире система объективного идеализма, конструкция, составленная из гипостазированных понятий, человеческих или божественных мыслей, совокупность априорных форм, чистых смысловых условий познания, амлегорическая картина, изображающая иерархию богов и. т. А. Вся эта необязательная разноголосица могла бы быть прекращена, если бы удалось найти у самого Пцатона разъяснения по поводу важнейших вопросов о сущности идеи, о взаимоотношении идей, об отношении вещи и идеи и т. А. Вопросы эти у Пцатона найти можно, а вот ответы на них в платоновских произведениях найти никак не получается, и сторонникам теории идей приходится в связи с этим ссылаться на будто бы так и не законченное при жизни Платона оформление этой теории, говорят о самокритике П^атона, о множественности вариантов теории идей и необходимости отделения ранней, «наивной», теории идей от Аругих, зрелых ее версий.

Безусловно, учитывая, что конструкция «теории илей» начала выстраиваться еще в Академии, вскоре после смерти Платона, когда была инициирована, вероятно, Спевсиппом, внутриакадемическая дискуссия об идеях, нужно признать, что в разных вариантах эта теория Аействительно стала важной составной частью платонической традиции. Но авторство этой теории принадлежит не Пцатону, а, скорее всего, академикам (некоторые из них, впрочем, как известно, вовсе отказались от учения об идеях). У самого же П^атона по поводу идей-эйдосов нет ни четкой однозначной терминологии, ни порядка в описании идей, ни системы, ни методологии. Характерно еще, что Платон вообще никогда не обсуждает вопрос об идеях как таковых, без отношения к тому, идеями чего именно они явАяются: идея прекрасного, идея справеАливого, иАея блага. В общем, как замечает Ю.А. Шичалин, «рассуждения Пцатона об идеях всегда были скорее возвышенными метафорами, нежели Аоказательными и в онтологическом плане определенными построениями» [Шичалин, 1989, с. LXI].

А^я чего Пцатону потребовалось обращение к концепту идеи, Аоставившее ему столько хлопот (которые Пцатон, в конце концов, благополучно переложиц на плечи своих будущих интерпретаторов)? Сам Пцатон сохраняет по этому поводу благородное молчание - ни в оАном из его произведений, вкАючая письма, не говорится, когАа и по какой причине у него появилась нужда в идеях. Интерпретаторы Пцатона, начиная с Аревних, неоднократно обращали внимание на то, что не Пцатону принаАлежит первенство в разработке концепции вечного, неизменного и неподвижного бытия: задолго до Платона философами Элейской школы была выдвинута концепция «бытия согласно 


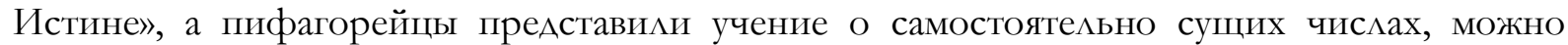
также вспомнить и об атомах Аемокрита, таких же вечных и неизменных. Эти учения были широко известны в Греции, и Платон также был прекрасно с ними знаком, так что в преАположении, что он мог заимствовать у своих предшественников материал Аля конструирования своих идей, нет ничего невероятного. Но А^я того, чтобы принять элейские или пифагорейские взгляды, Пцатону нужны были весомые собственные причины. Такие, в частности, как те, на которые указывает, свидетельство Аристотеля: «Смолоду сблизившись, прежде всего, с Кратилом и гераклитовскими воззрениями, согласно которым все чувственно воспринимаемое постоянно течет, а знания о нем нет, Пцатон и позже держался таких же взглядов. А так как Сократ занимался вопросами нравственности, природу же в целом не исследовал, а в нравственном искал общее и первый обратил свою мысль на определения, то Пцатон, усвоив взглял Сократа, доказывал, что такие определения относятся не к чувственно воспринимаемому, а к чему-то Аругому, ибо, считал он, нельзя Аать общего определения чего- иибо из чувственно воспринимаемого, поскольку оно постоянно изменяется. И вот это Аругое из сущего он назвац илеями, а все чувственно воспринимаемое, говориц он, существует помимо них» [Met. 987a.30-b10]. Таким образом, сама сократическая традиция поиска общих определений побудила Пцатона обратиться к учениям о вечном и неподвижном бытии тогАа, когАа возникАи трудности с поиском надежных оснований нравственности.

Направление поиска было задано Платону не только Сократом, но и Гераклитом, точнее, гераклитовцем Кратилом, тем самым, который «под конец пришел к мнению, что не слелует ничего высказывать, и только шевелил пальцем, а также упрекал Гераклита за то, что тот сказал “нельзя дважды войти в одну и ту же реку", поскольку сам полагал, что нельзя войти даже один раз» [Met. 1010a.10-15]. Эта радикальная версия учения о всеобщей изменчивости произве а, без сомнения, сильное впечатление на Пцатона, особенно если учесть то, что какое-то время он был близок с Кратилом. Аристотель говорит о Кратиле как о первом учителе юного ПАатона, хотя к этому сообщению следует отнестись с разумной слержанностью, поскольку неизвестно, когда именно Платон общался с Кратилом. Некоторые говорят, что это было не до встречи с Сократом, а, возможно, одновременно с Сократом или даже после казни последнего (Апулей, Олимпиодор, Аноним). Если так, то Пцатон пришел к беседам с Кратилом уже с полным осознанием того, к чему может привести такой крайний релятивизм и готов был ему противостоять.

В целом ряде Аиалогов, вкАючая и тот, который назван именем Кратила, Пцатон резко отрицательно отзывается о тех, кто придерживается учения о всеобщей текучести. Может сложиться впечатление, что сам он это учение не признает, тем более что местами Пцатон прямо и неАвусмысленно говорит об этом взгляде как совершенно неприемлемом: «... и несвойственно разумному человеку, обратившись к именам, ублажать свою Аушу и, Аоверившись им и их присвоителям, утвержАать, будто он что-то знает (межАу тем как он презирает и себя, и вещи, в которых будто бы нет ничего устойчивого, но все течет, как дырявая скудель, и беспомощно, как мюАи, страАающие насморком), и думать, и располагать вещи так, как если бы все они были влекомы течением и потоком» [Crat. 440c-d]. ОАнако сама по себе текучесть чувственного бытия (aistheton) Пцатоном как раз и не оспаривается, но его возмущает и даже пугает мнение, которое сводит прироАу вещей к оАной только этой текучести. Сторонники этого мнения появились тогАа, когАа искаженное понимание вещей было принято за истинную природу самих вещей: «самые Аревние АюАи, присваивавшие имена, как и теперь большинство мудрецов, от непрерывного вращения головой в поисках объяснений вещам всегАа испытываАи головокружение, и поэтому им казалось, что вещи вращаются и несутся в каком-то вихре. И разумеется, и те и Аругие считают, что причина такого мнения не внутренний их недуг, но таковы уж вещи от природы: в них нет ничего устойчивого и надежного, но все течет и несется, все - в порыве и вечном становлении. [Crat. 411b-c]. И, что Аля Платона важнее всего, такое видение бытия самого человека делает частью 
непрерывного потока изменений, в котором он бессмысленно мечется без какой-либо надежной опоры. Именно так он в «Теэтете» рисует гераклитовцев: «.. с самими эфесцами, кичащимися своей опытностью, разговаривать не мегче, чем с разъяренными слепнями. Прямо как стоит в их писании, они вечно несутся, а задержаться на предмете исследования или вопросе, спокойно и чинно отвечать или спрашивать менее всего им присуще. Скорее можно сказать, что это им и вовсе не свойственно - покоя ААя них не существует. А если ты кого-нибудь о чем-либо спросишь, то они обстреляют тебя, вытаскивая, как из колчана, одно загадочное речение за Аругим, и если ты захочешь уловить смысл сказанного, то на тебя обрушится то же, только в переиначенном виде, и ты с ними никогАа ни к чему не придешь. Аа и межАу собою им это не удается, благо они вовсю остерегаются, как бы не оказалось чего-либо прочного в их рассуждениях или в их собственных Аушах, считая, как мне кажется, это застоем. А с ним они страшно воюют и по возможности отовсюду его изгоняют» [Theaet. 79e; 180b]. Потому и научить такие «мудрецы» никого не смогут, «ведь у них никто не становится учеником Аругого - они объявляются сами собой, по вдохновению, и один Аругого почитает невежАой» [Theaet. 180c].

Стремление избежать печальной участи таких Аюдей, живущих без смысла, знания и порядка - вот важнейшая из причин обращения Платона к идеям, в которых он находит воплощение истинной природы вещей. Все то, что в чувственном измерении бытия непрестанно изменяется, возникает и уничтожается и вновь возникает, вся эта откровенно раздражающая Платона пестрота (роikilia), о которой ни знать, ни сказать ничего определенного нельзя, когда фюсис расползается подобно прелой тряпке в руках, - все это воспринимается Пцатоном как то, через что следует переступить на пути к истинной жизни. И делая этот шаг впереА, отправляясь по ту сторону изменчивых вещей, наАо быть убежАенным в том, что там, за ними, есть надежная почва вечного, неизменного, истинного бытия. А. Ж. Фестюжьер замечает это обстоятельство: «Будучи абсолютной, неАоказуемой и недоказанной, ИАея с самого начала облаАает всеми признаками объекта веры» [Фестюжьер, 2009, с. 77]. Понятая таким образом идея раскрывает свой нуминозный характер, она в большей мере предмет веры и воображения - миф, а не философская категория, а сам Платон - не философ, а мифотворец, религиозный пророк и учитель.

\section{СПИСОК ИСПОАЬЗОВАННЫХ ИСТОЧНИКОВ}

Аосев А. Ф. Очерки античного символизма и мифологии / сост. А. А. Тахо-Тоди; общ. ред. А. А. Тахо-Годи и И. И. Маханькова. М.: Мысль, 1993. 959 с.

Платон. Сочинения: в 4 т. / пер. с Аревнгреч.; общ. реА. А. Ф. Аосева и В. Ф. Асмуса. СПб.: ИзА-во С.-Петерб. ун-та; ИзА-во Олега Абышко, 2006-2007.

Фестюжьер А.-Ж. Созерцание и созерцательная жизнь по Платону / пер. с франц. А. С. Гагонина. СПб.: Наука, 2009. 497 с.

Сеземан В. Э. Этика Платона и проблема зла / пер. с нем. и послесл. В. Н. Белова. Кантовский сборник. 2010. Вып. 1. С. 75-89.

Шичалин Ю. А. Ава варианта платоновского «Федра». Платон. Федр. М.: Прогресс, 1989. C. VIII-LXXIII.

Hyland D. A. Against a platonic theory of forms. Plato's Forms. Varieties of Iterpretation / ed. by W. A. Welton. Lanham: Lexington Books, 2002. pp. 255-287.

\section{Прокопенко ВАадимир ВАадимирович}

Аоктор философских наук, профессор кафедры теоретической и практической философии имени профессора И. Б. Шада

Харьковский национальный университет имени В. Н. Каразина

площадь Свободы, 6, Харьков, 61022

E-mail: pvlad99@gmail.com

ORCID: https://orcid.org/0000-0001-5816-3505

Статья поступила в редакцию: 15.10.2018

У тверждена к печати: 19.11.2018 


\section{БААГО ТА ІНШI IАЕЇ П АТТНА}

\section{Прокопенко Володимир Володимирович}

Аоктор філософських наук, професор кафелри теоретичної і практичної філософії імені професора Й. Б. Шада

Харківський національний університет імені В. Н. Каразіна

майАан Свободи, 6, Харків, 61022

E-mail: pvlad99@gmail.com

ORCID: https:// orcid.org/0000-0001-5816-3505

У статті аналізується вчення Пцатона про іАеї, розглядається питання про те, чи є виправданим використання поняття «теорія ідей Платона», відзначено, що погляди Платона 3 цього приводу є непослідовними та суперечливими і, вілповіАно, ніякої теорії ілей у Платона насправді немає. Особливе місце у вченні Пцатона займає іАея блага, про яке він говорить як про найвищу іАею. Аналіз платонівського розуміння блага показує, що віАносно цієї ілеї у Платона також немає чіткого й артикуцьованого пояснення. У Пцатона є іАея блага, але у нього немає концепції блага, і він говорить про благо без розгорнутої дефініції цього поняття. Аля роз'яснення змісту іАеї блага Пцатон користується алегоріями. НайвіАомішою з цих алегорій є уподібнення блага Сонцю в діалозі «Держава». У статті ставиться питання про те, навіщо Пцатону знадобились поняття «іАея» $\mathrm{i}$ «благо», якщо у нього немає чіткого розуміння того, чим вони є. Автор вважає, що цьому є дві причини. Перша 3 них носить педагогічний характер: Платон навмисно не дає вілповіАі на жодне $з$ важливих питань, пов'язаних з існуванням іАей, віАношенням ілеї і речі, віАношеннями між самими ідеями. Платон розкриває всі ці труднощі, але надає своїм читачам можливість самостійно осмислити ці проблеми. Аруга причина полягає в тому, що платонівські іАеї не призначені Аля пізнання буття, вони не є філософськими категоріями. Це особливо очевиАно у випалку іАеї блага. Автор статті робить висновок про те, що поняття блага спочатку з'явАяється в етиці Пцатона й тільки після цього набуває онтологічного сенсу. Пцатонівська онтологія взагалі покликана Аати обгрунтування його етиці та політиці. Виходячи 3 цього, автор доходить висновку, що іАеї Пцатона мають релігійну природу. ВіАповіАно, до Пцатона треба віАноситись як до міфотворця та релігійного вчителя.

Ключові слова: Платон, ілея, єАине, алегорія, міф.

\section{GOOD AND OTHER IDEAS OF PLATO}

\section{Prokopenko Vladimir V.}

Doctor of Science, Professor, Department of Theoretical and Practical Philosophy

named after Professor J. B. Schad

V. N. Karazin Kharkiv National University

6, Svobody sqr., 61022, Kharkiv, Ukraine

E-mail: PVlad99@gmail.com

ORCID: https:// orcid.org/0000-0001-5816-3505

\section{ABSTRACT}

The article analyzes Plato's doctrine of forms, discusses whether the use of the concept of Plato's theory of ideas (forms) is justified, noted that Plato's views on this matter are inconsistent and contradictory and that there is, in fact, no theory of forms in Plato's philosophy. A special place in the philosophy of Plato is the idea of good, which he treats as the highest idea. An analysis of the Platonic understanding of good shows that there is no clear and articulated explanation for Plato in relation to this idea. Plato has the idea of good, but he has no conception of good, and he speaks about good without the expanded definition of this concept. To explain the content of the idea of good, Plato uses allegories. The most famous of them is the likeness of the good of the Sun in the «Politeia» dialogue. The article poses the question of why Plato needed the concept of «idea» and «good» if he did not have a clear 
understanding of what they are. The author believes that there are two reasons for this. The first of them is pedagogical: Plato deliberately does not answer any of the important issues related to the existence of ideas, the relationship of ideas and things, the relationship between the ideas themselves. Plato reveals all these difficulties, but gives his readers the opportunity to understand these problems independently. The second reason is that Plato's ideas are not intended for the knowledge of being, they are not philosophical categories. This is especially evident in the case of a good idea. The author of the article concludes that the notion of good first appears in Platos ethics and only then becomes ontological. Plato's ontology in general is intended to justify his ethics and politics. Proceeding from this, the author comes to the conclusion that the ideas of Plato have a religious nature, and Plato himself is not a philosopher, but a myth-creator, a religious prophet and a teacher.

Keywords: Plato, idea, unity, good, allegory, myth.

\section{REFERENCES}

Losev, A. F. (1993). Essays on Ancient Symbolism and Mythology. Moscow: Nauka. (In Russian).

Plato. (2006-2007). Works (Vol. 1-4). (A. F. Losev \& V. F. Asmus, Eds.). Saint Petersburg: St. Petersburg University Press; Oleg Abyshko Publishing House. (In Russian).

Festugière, A.-J. (2009). Contemplation and contemplative life according to Plato. (A. S. Gagonin, Trans.). Saint Petersburg: Nauka. (Original work published 1978). (In Russian).

Sesemann, W. (2010). Plato's Ethics and the Problem of Evil. (V. N. Belov, Trans.). Kantian journal, 1, 75-89. (Original work published 1912). (In Rusian).

Shichalin, Y. A. (1989). Two versions of Plato's «Phaedrus». In Y. A. Shichalin (Ed.), Plato. Phaedrus (pp. VIII-LXXIII). Moscow: Progress. (In Russian).

Hyland, D. A. (2002). Against a platonic theory of forms. In W. A. Welton (Ed.), Plato's Forms. Varieties of Interpretation (pp. 255-287). Lanham: Lexington Books.

Article arrived: 15.10 .2018

Accepted: 19.11.2018 